\title{
The clotting system in decapod crustaceans: History, current knowledge and what we need to know beyond the models
}

\author{
Rolando Perdomo-Morales ${ }^{\mathrm{a}}$, Vivian Montero-Alejo ${ }^{\mathrm{a}}$, Erick Perera ${ }^{\mathrm{b}}$ \\ ${ }^{\mathrm{a} C e n t e r}$ for Pharmaceuticals Research and Development. Ave. 26 No. 1605, Esq. \\ Puentes Grandes. Plaza. 10600. La Habana. Cuba. \\ ${ }^{b}$ Nutrigenomics and Fish Growth Endocrinology Group, Institute of Aquaculture Torre \\ de la Sal, CSIC, Castellón, Spain \\ Corresponding Author: Rolando Perdomo-Morales (rolando.perdomo@ cidem.cu and \\ perdomo.morales@gmail.com)
}

\begin{abstract}
Hemolymph coagulation is among the major arms of the humoral immune response in crustaceans. According to the current model, hemolymph clotting in decapod crustacean relies mostly on the polymerization of the plasmatic clotting protein $(\mathrm{CP})$ which is directly promoted by calcium-depended transglutaminase (TGase) released from hemocytes upon microbial stimulus or injury. However, the type of hemocytes containing TGase, and hence how the TGase is released, might vary among species. Thus, we discourse here about possible mechanisms for clotting initiation. On the other hand, the initiation of coagulation reaction in the absence of microbial elicitors is poorly understood and seems to involve hemocytes lability, yet the mechanism remains unknown. A cellular clottable protein called coagulogen, different to the plasma $\mathrm{CP}$, occurs in several species and could be related with the immune response, but the biological relevance of this protein is unknown. It is also demonstrated that the clotting response is actively involved in defense against pathogens. In addition, both TGase and the CP show pleiotropic functions, and although both proteins are relatively conserved, some of their physic-chemical properties vary significantly. The occurrence of differences in the clotting system in crustaceans is conceivable given the high number of species and their diverse ecology. Results from still non-studied decapods may provide explanation for some of the issues presented here from an evolutionary perspective.
\end{abstract}

Keywords: Crustacean; clotting; coagulation; clotting protein; hemolymph; hemocytes; transglutaminase; invertebrates 


\section{Introduction}

The main function of the clotting system is the formation of a stable clot to seal wounds preventing the loss of body fluids (i.e. maintaining hemostasis) [1]. In addition, the coagulation reaction in invertebrates, along with the prophenoloxidase-activating system (proPO system) and the production of antimicrobial peptides, is a key component of the humoral arms of the innate immune response [1-3]. Blood clotting is probably the best-known biological system in vertebrates [4] and consequently it has been thoroughly reviewed (See [5-7] for recent reviews). Its primary role in maintaining vertebrate hemostasis has been widely documented [5]. Throughout decades, new knowledge on vertebrate coagulation has been regularly incorporated into different models. The clot formation has been largely explained by the coagulation cascade model described in the 1960s. The clotting cascade is composed by trypsin-like serine proteases and cofactors that lead to the formation of fibrin clots. The cascade is divided into intrinsic and extrinsic pathways, which are initiated by different stimuli and factors but converge on Factor X activation in a Y-shape scheme. Although the coagulation cascade model is still used nowadays, it fails to explain several aspects of vertebrate hemostasis and therefore has been often replaced by the Cell-based model [7], in spite of the fact that both models for coagulation are relatively consistent through vertebrates.

On the other hand, it has been stated that hemolymph clotting in the Phylum Arthropoda shows high level of variation of clot components among different groups and even within them, which is probably due to the extensive difference in their ecology [3]. Among arthropods, the coagulation process has been exhaustively studied in horseshoe crabs (e.g. Limulus polyphemus) [2, 8, 9], which are marine ancient arachnids (Subphylum Chelicerata). Hemolymph clotting in horseshoe crabs is based on a serine proteinase cascade which is activated by microbe-associated molecular patterns (MAMP) from the cell wall of microorganisms, such as lipopolysaccharides (LPS) from Gram negative bacteria and $\beta$-1,3-glucans from fungi. All elements of the horseshoe crab clotting cascade are in an inactive form or zymogens inside amebocytes granules. The last component is the clottable protein, coagulogen, which is proteolytically converted to insoluble coagulin gel composed of non-covalent homopolymers [10]. Likewise, the coagulation system has been extensively studied in insects (Subphyllum Uniramia), and particularly in Drosophila, in which studies on mutants and lines with reduced expression of clotting-factors have indicated that sealing wounds may rely on 
redundant mechanisms [11], but the detailed mechanism is still not completely understood (for review see [12]).

From the Subphylum Crustacea, only decapods (Class Malacostraca, Order Decapoda) have received significant research attention, probably due to their larger size and economic importance when compared to other members of the group. It is noteworthy that reviews dealing solely with the clotting system in decapod crustacean are only found in the 1980s of the past century $[13,14]$. Since then, the topic has been partly included to a different extent in several reviews dealing with the immune response $[2,8$, 15-17] or the clotting system $[1,3,18,19]$ in invertebrates. Moreover, in most of these reviews the clotting mechanism of crustaceans is explained using the freshwater crayfish Pacifastacus leniusculus model, since this species has been the most extensively studied and has provided useful models for explaining the crustacean immunity [20]. The economic importance of shrimp culture might explain the growing number of studies dealing with shrimp immunity [21], including their clotting system [22].

Thus, most knowledge about the clotting system in decapods comes from few species of crayfish and shrimp, which seem to share a general clotting mechanism. While these research efforts have significantly increased our understanding about the coagulation process in crustaceans, the remarkable diversity of crustacean species and their habitats might lead to the occurrence of species-specific differences. This review attempts to provide an updated encompassing view of the clotting reaction and its functions in decapods. We have highlighted differences among species and unanswered observations that go beyond the useful models currently used to explain the clotting reaction in those organisms. In order to do this, we reviewed studies from the 80's which dealt with a larger spectrum of crustacean species. Some of the observations in these studies such as the biological significance of cellular coagulogen found in some crabs or the main hemocyte type responsible for initiating the clotting reaction are still poorly understood.

\section{The clotting process}

\subsection{Unequal interplay among cellular and humoral factors}

As early as the beginning of the past century, Tait defined three mechanisms of coagulation in crustaceans grouped as type A, B and C [23]. Group A is characterized by the rapid agglutination of hemocytes without plasma clotting (e.g. the crabs Loxorhynchus grandis, Cancer pagurus and Maja squinado). In this case, a dense 
network of hemocytes is enough to seal the wound, and clotted hemocytes are indeed connected through polymerized fibers. Type B involves cell coagulation followed by plasma coagulation (e.g. the lobster Homarus americanus, and the crabs Macropipus puber and Carcinus maenas), and in type $\mathrm{C}$, the hemocytes are rapidly lysed and the plasma is clotted immediately resulting in low cell aggregation (e.g. shrimps and spiny lobsters) $[24,25]$. Some authors have proposed that type A might represent the most primitive condition [26].

In the 80 's, Ghidalia suggested that the occurrence of the three coagulation patterns was due to different concentration of $\mathrm{CP}$, formerly named fibrinogen or plasma coagulogen, among species belonging to each Tait's category [27]. Thus, species exhibiting type A coagulation contain the smallest amount of $\mathrm{CP}$, those with type $\mathrm{C}$ have the most, and type B has a middle concentration. Accordingly, in species with type A coagulation, there is such a low concentration of $\mathrm{CP}$ that plasma clot formation is either not possible or incomplete. The study concluded that the classification proposed by Tait was too schematic as the same clotting process was present in all crustacean species evaluated [27].

Ten years later, Hose and collaborators proposed a different explanation for the Tait classification, which is rather related with the proportion of hyaline cells in the hemolymph [25]. It is widely accepted that decapod crustacean hemolymph mainly contains three types of hemocytes: hyaline, semi-granular and granular [25, 28, 29]. Hose observed a higher percentage of hyaline in Type C (50-70 \% of total hemocytes) species, while it is reduced from type B (34\%) to type A (19\%). Therefore, it was suggested that the coagulation patterns described by Tait are not three different mechanisms (i.e. type A, B or C), but represent a proportional response to the percentage of hyaline cells. Such disparity on differential hemocyte counts among crustaceans has been validated in more recent studies [30, 31].

Hose's proposal to explain the different coagulation patterns observed in crustaceans seems plausible since transglutaminases (TGase), the enzyme responsible for the polymerization of $\mathrm{CP}$, was apparently localized mostly in hyalines in several species [24]. In addition, functional studies conducted at that time suggested that hyaline cells initiate plasma clotting by cytolysis and release of cytoplasmic factors [14, 25, 28]. However, some controversy which is still unsolved, was already evident at that time concerning whether hyalines or granular hemocytes trigger the coagulation reaction 
[28]. Unfortunately, most studies about the classification pattern proposed by Tait dates from the 80 s and early 90s, and afterwards this issue has been barely addressed. More recent studies have shown that TGase are located in both hyaline and semigranular cells in the spiny lobster $P$. japonicus [32], while in the freshwater crayfish they occur in both semi-granular and granular [33]. In the shrimp L. vannamei, TGase are mostly found in hyaline, although some gene expression has been also evidenced in semi-granulocytes and granulocytes [34]. Other studies in shrimps confirm the expression of TGase in hemocytes [35-38], but no attempts were made to identify the hemocyte type having the higher TGase expression or activity. In general, it seems that as in spiny lobsters [32], TGase in shrimp is mainly localized in hyalines [39], and coincidently, both species belong to type $\mathrm{C}$ category. However, there is some variability as few non-decapod crustaceans such as branchiopods contain only one type of nonhyaline hemocytes [26], this perhaps is explained by the early divergence between the linage giving rise to branchiopods and the linage of other crustaceans including decapods such as shrimp, crayfish and lobster [40], or by different evolutionary histories. Therefore, it is still not known whether it is the differences in CP concentrations, the cellular type containing TGase, or both, what causes the hemolymph clotting patterns described by Tait in crustacean.

According to the current model, which is mostly based on research findings in the freshwater crayfish P. leniusculus, the clotting of hemolymph in crustaceans is produced upon releasing of TGase from hemocytes and other tissues that, in presence of calcium ions, promote the rapid polymerization of the plasmatic $\mathrm{CP}$ into long and flexible chains that occasionally branch $[2,19,41]$. Due to the mere presence of both purified CP and TGase are enough to produce a firm gel [19], it seems that conversely to vertebrates and horseshoe crabs, the clotting process in crustaceans is likely to involve a single stage. The first clue suggesting a one-stage clotting process was found in the spiny lobster $P$. interruptus [42]. It was demonstrated that the $\mathrm{N}$-terminal sequence of the so-called fribinogen remain unchanged after clot formation, suggesting that it was not previously digested by proteolytic enzymes. In addition, TGase from outer species such as guinea pig [43] and humans (i.e., Factor XIII) [44], were able to clot the plasma of crayfish and crabs, respectively, with no other intermediates. On the other hand, early studies reported the presence of a cellular coagulogen different to the CP from plasma, for instance, in the hemocyte granules from the lobster Homarus vulgaris, and in the hemocytes from the crab Ovalipes bipustulatus and the prawn 
Sicyonia ingentis $[13,45]$. The clottable factor from the hemocytes of the sand crab $O$. bipustulatus is a $70 \mathrm{kDa}$ single-chain protein containing disulfide bridges [46, 47]. This coagulogen is hydrolyzed by trypsin, and clots after limited proteolysis with thrombin combined with human factor XIII and calcium, thus resembling the clotting process in mammals, yet the meaning of this in vitro observation is unclear and probably physiologically irrelevant. The crab coagulogen also differs from plasma CP typical from crustaceans in total amino acid composition [48].

On the other hand, Söderhäll and collaborators also found over twenty years ago that $\beta$ 1,3-glucans and LPS directly induce coagulation of the hemocyte lysate of the crayfishes $P$. leniusculus [49] and A. astacus [50], with no participation of plasma components. Similar to the clotting process in horseshoe crabs, this reaction involves serine proteases. However, conversely to the nature of the clot produced by plasma $\mathrm{CP}$ in crustaceans and by the amebocyte lysate of horseshoe crabs, the clot produced in the crayfish hemocyte lysate could be easily disrupted by shaking the test tube $[43,49]$. The biological meaning of this clotting response, if any, is still unknown and no further studies about this process have been reported since then.

In addition, LPS or endotoxin induces the hemocyte lysate of the spider crab Maja squinado to clot in a similar way as the horseshoe crab L. polyphemus [51]. In the lobster H. vulgaris and the crayfish Astacus leptodactylus, a precipitation or clotting reaction induced by LPS and $\beta$-1,3-glucans was observed, but the presence of cellular coagulogen was ruled out [52]. In the freshwater crab Sudanonautes africanus, LPS activates components in the hemocytes that in the presence of calcium produce the clotting of plasmatic proteins, probably the CP [53], which suggest the participation of an unknown factor other than CP and TGase in the process.

LPS can induce clotting of amebocyte lysate of the snail Achatina fulica in a reaction mediated by pattern recognition receptors and serine proteinases, which resembles the horseshoe crab clotting reaction $[54,55]$. LPS fails to induce hemocyte lysate clotting in crustacean species that seems to contain cellular coagulogen such as $O$. bipustulatus [46] and S. ingentis [45], and in other non-crustacean invertebrates also containing cellular coagulogen such as the sea star Asterias forbesi [56]. It is worth mentioning that administration of bacteria or their MAMPs into several crustacean species produce intravascular coagulation (i.e., hemocyte clotting), leading to hemocytopenia, incoagulable plasma and death $[13,57,58]$. 
It is noteworthy that no other reports regarding the occurrence of cellular clottable protein in crustaceans has been made in the last years and the reasons behind are not obvious from the literature. The lack of such information is probably because most research efforts in crustaceans clotting have focused on a few crayfish and shrimp species, or simply because the issue has not been addressed. Considering the high variability and numbers of crustacean species, there is a need for further research to clarify, in a broader range of crustacean species, whether the intracellular clottable protein is present or not, and its biological significance.

Whereas there is a wide variation in the presence of "cell coagulogen" and its relation with the response to microbial elicitors, the ability of plasma-free cell lysate to clot as a direct and proportional response to the presence of microbial elicitors such as LPS and $\beta-1,3$-glucans has so far been truly demonstrated only in horseshoe crabs. The clotting cascade of horseshoe crabs is used as a reagent for the in vitro detection and quantification of LPS, a molecule widely known for its profound deleterious effect on the human health when reaching systemic circulation [59]. The reagent and the assay are known as Limulus Amebocyte Lysate (LAL), and the assay is claimed by most regulatory agencies as part of the quality control needed for the approval and commercialization of end-product pharmaceutical and biotechnological injectable products.

It has been suggested that the proPO system in crustaceans is the counterpart of the clotting system from horseshoe crabs, since they share remarkable similarities, though the outcome differs [50,60,61]: a) Both systems are inside the cells and are released in response to microorganisms, b) They are activated by minute amounts of microbial elicitors through pattern recognition proteins, c) They are composed by enzymatic cascades including trypsin-like serine proteases which are regulated by protease inhibitors, d) They often require the presence of divalent cations for activity and e) The final component of the cascade causes the biological response (e.g. clotting in horseshoe crabs and melanization in crustaceans). In fact, we haven't found a clotting system like that from horseshoe crabs in lobsters (unpublished results), but we have proposed a method for the detection of LPS, 1,3- $\beta$-glucans and peptidoglycan based on the proPO activating system of Panulirus argus (US 2014/0356889 A1), which resembles several features of LAL assay. 


\section{Main players of crustacean clotting reaction}

\subsection{Clotting Protein}

The CP in crustaceans have no structural similarities with fibrinogen from vertebrates or clottable proteins from other arthropods such as the coagulogen from Limulus, and thus CPs from crustaceans represent a separated group of clot-forming proteins [2, 8, 41]. Therefore, past claims identifying fibrinogen as the protein responsible for clot formation in crustaceans due to functional similarity are incorrect. The first mention of the term "clotting protein" was by Horn and Kerr in 1969 to differentiate a clottable protein found in the hemolymph of Callinectes sapidus, which occurs in similar quantities in plasma and in serum, and therefore unlikely to correspond to fibrinogen as considered in classical serology [27]. The CP is also named clottable protein [39] and very high-density lipoprotein (VHDL) [62].

The first CP partially characterized in crustaceans was isolated from plasma of the spiny lobster Panulirus interruptus [42, 63]. It is a lipoglycoprotein of $420 \mathrm{kDa}$ composed of two identical $210 \mathrm{kDa}$ subunits covalently linked by disulfide bridges [64]. CP was then thoroughly studied for first time in the freshwater crayfish P. leniusculus [41, 43]. It is a high-density lipoprotein comprising 1721 amino acids, which is also disulfide-linked homodimers of $210 \mathrm{kDa}$ subunits. The occurrence of CPs sharing similar amino acid composition and $\mathrm{N}$-terminal sequence was thereafter described in the white shrimp Penaeus vannamei [48, 65], the pink shrimp Farfantepenaeus paulensis [37], the sand crayfish Ibacus ciliatus [66], the tiger shrimp Penaeus monodon [39, 67], the kuruma prawn Marsupenaeus japonicus [65] and the Chinese shrimp Fenneropenaeus chinensis [68].

CPs from related marine penaeid shrimps seem to have similar properties, and their genes are apparently highly conserved [65]. For instance, similarity of CP sequence from the M. japonicus and P. monodon is $80 \%$, although CPs from penaeid shrimps differed from those in freshwater crayfish (38\% similarity) [65]. This divergence is expected as penaeid shrimps early diverged during decapod evolution and thus, are distant from more recent groups such as crayfish and lobsters [69]. In agreement with these evolutionary considerations, the CP in crayfish contains $20 \%$ sugar (six potential Asn sites), whereas in P. monodon is lower (3.8\% with four potential Asn sites) [67]. In addition, through immunodiffusion experiments, it has been found that polyclonal antibodies rose against CP from $P$. monodon cross-react with CP from $M$. japonicus, but not with CP from the crayfish Procambarus clarki [39]. Chemical-physical 
differences were also evidenced as CP from $P$. leniusculus and $P$. interruputs precipitated from whole plasma by isoelectric precipitation at $\mathrm{pH} 6$ and low ionic strength, but the same condition has no effect on CP from P. vannamei [48]. CP subunits can be divided into a N-terminal vitellogenin-like domain 1 (around 80 amino acids residues), which is rich in Lys residues, and a C-terminal long vitellogeninlike domain 2 rich in Gln residues [70]. The C-terminal or the vitellogenin domain 2 includes a cysteine-containing stretch with a sequence similar to the D domain of the von Willebrand factor, a $250 \mathrm{kDa}$ protein involved in blood coagulation of mammals [41]. Each CP subunit could provide at least one Lys and one Gln residue available for cross-linking by TGase $[19,70]$. During the polymerization process, the CP assembles into long and flexible chains with occasional branch points, where each CP subunit interact at localized points instead of interacting through large surfaces [19, 41]. It is worth mentioning that proteins containing fibrinogen-related domains have been identified in numerous non-crustacean invertebrates, where they are related with defense against pathogens and other biological functions but not with coagulation, suggesting that the role of fibrinogen as a clottable protein in vertebrates arose more recently [71]. In crustaceans, proteins containing a fibrinogen-like domain have been identified in the melanization inhibition protein (MIP) from the crayfish P. leniusculus [72] and P. monodon [73]. This protein is implicated in the regulation of the melanization reaction promoted by the proPO system, for which the fibrinogen-related domain is essential. In addition, fibrinogen-like domains are in two novel ficolin-like proteins from P. leniusculus [74], and in the C-terminal domain of a calcium-dependent lectin (MjFREP1) from Marsupenaeus japonicus, a protein involved in the immune response [75].

Instead, CP sequences from crustaceans are homologous to vitellogenins, indicating that they are evolutionary related families [41], probably by divergent evolution [65], but they should not be considered as true vitellogenins since they completely have different functions. Besides, vitellogenins are expressed only in females of egg-laying animals, whereas CPs are constitutively expressed in both sexes [41]. Finally, conversely to other major plasma proteins such as hemocyanin and $\beta-1,3$ glucan binding protein (BGBP), which are synthetized in hepatopancreas [76-79], CP seems to be mainly produced in other tissues like the gill, the central nerve system, the lymphoid organ and the heart $[65,67,80]$, although in some species it is also expressed in the hepatopancreas [41], but to a lower extent [67]. The effects of the variation of CPs among crustaceans in 
terms of quantity, molecular structure and functional properties on the coagulation process are still not completely understood.

\subsection{Transglutaminases}

TGase (EC 2.3.2.13) are calcium-dependent enzymes that catalyze acyl transfer reactions, which in the absence of small molecular weight amines, promote the formation of $\varepsilon$-( $\gamma$-glutamyl)lysine bonds between the $\gamma$-carboxyl group of a glutamine residue in one polypeptide chain and the $\varepsilon$-amino group of a lysine residue in a second polypeptide chain, thus promoting the cross-linking of proteins $[81,82]$. TGase actively participate in coagulation in both invertebrate and vertebrates, although at different stages [1], and it might constitute the basis for the coagulation process in the animal kingdom [44]. Crustacean TGases involved in hemolymph coagulation do not exist as proenzymes, instead they are latent inside the cells [83], where they are probably kept inactive due to the low calcium concentration and the high GTP content in this compartment, as previously described for cytoplasmic TGase 2 from mammals [84]. TGase become activated with plasma calcium upon releasing from the cells [82, 83]. The calcium binding of TGase is required to unmask the cysteine residue in the active site, and also to induce important conformational changes that expose key residues engaged in the control of substrate access to the binding site [83, 85]. It was recently found that astakine, a hematopoietic cytokine from crayfish, is a competitive inhibitor of crayfish TGase and reduce TGase-mediated CP crosslinking, which represent a novel control of TGase activity in crustaceans probably involved in regulating hematopoiesis and wound healing [86].

The first TGase characterized in crustaceans were from $P$. leniusculus, where they are a protein of about $86 \mathrm{kDa}$ [33]. Subsequently, it has been characterized in the shrimps $P$. monodon and M. japonicus [35, 36, 87], F. chinensis [38], L. vannamei [34] and in the prawn Macrobrachium rosenbergii [88].

In shrimps, two types of TGase were identified, which accordingly to phylogenetic analysis can be separated into two groups, Type I and Type II [35, 36, 89]. The expression of TGases can be modulated by microbial stimuli and its expression level is related with success against microbial infections [22]. The Type II TGase described in L. vannamei [89] and P. monodon [36] seems to be the one most engaged in hemolymph coagulation. 
Primary sequence comparison reveals significant homology among TGase from crustaceans and to a lesser extent with TGase from other arthropods and vertebrates [33, $34,88,89]$. Amino acid residues in the catalytic regions are fully conserved and the residues comprising the calcium-binding site share significant homology. In addition, a variable number of RGD (Arg-Gly-Asp) motifs are present in most crustacean TGase [34, 65, 88, 89], and their positions are markedly conserved across invertebrates [87]. The RGD motif is present in most ligands that bind to integrin receptors [90], and is probably implicated in cell adhesion, cell migration and extracellular matrix adhesion $[91,92]$. Thus, different to $\mathrm{CP}$, which appear to show greater variation among crustaceans, TGase are more conserved within arthropods.

\section{Initiation of the clotting response}

The coagulation reaction takes place immediately upon TGase release from hemocytes, which seems the limiting step. Even though the releasing mechanism is still unknown [16], some findings might offer clues about TGase transport to the extracellular space, whose could also help direct future research efforts in this field. TGase from vertebrates and invertebrates lacks a signal peptide (i.e. they are leaderless proteins) [35, 83], and therefore cannot be secreted by the classical secretory pathway of proteins [93]. In addition, TGases involved in hemolymph clotting in crustaceans are located in the cytoplasm [38, 87, 88]. Cytoplasmic proteins lacking a signal peptide that functions outside the cells are transported into the external milieu through the so-called unconventional protein secretion (UPS) system [93, 94].

A recent study in Drosophila showed that TGase-A, the TGase probably related with hemolymph clotting, is secreted by UPS through an exosome-dependent secretion pathway mediated by two sequential fatty acylations [95]. It was also found that TGaseA was secreted in response to calcium signaling and uracil, a pathogenic bacteriaderived substance. However, MAMP such as lipopolysaccharides and peptidoglycans fails to induce TGase-A secretion.

In addition, from the nine families of TGase from mammals, TGase 2 is the one found in the cytoplasm [96]. TGase 2 can be secreted by different UPS mechanisms such as exosome [97], endosome [98], and membrane pore formation [99]. The occurrence of different UPS mechanism could be related with the conditions triggering their release and the cell type [94]. 
Therefore, considering all the stated above, it is tempting to speculate that TGase from crustacean hemocytes could probably be secreted through as yet unidentified UPS pathway.

On the other hand, it has been suggested that secretion of TGase is likely to be accomplished concomitantly with the proPO system and other humoral factors induced by microbial elicitors or injury $[2,15,17,60,91]$. Most knowledge about the activation and development of both the proPO and clotting system in crustaceans has been uncovered by Söderhäll and collaborators in the freshwater crayfish P. leniusculus. But before go any further, it is important to know that conversely to insects, where the relationship of the proPO system and coagulation is evident $[11,100]$, this relationship is unclear in crustaceans. In addition, the proPO zymogen is a cytoplasmic leaderless protein that is released by an unknown UPS mechanism, probably involving caspase-1 activity [101], or another pathway that remains to be elucidated. Other humoral components of the proPO system are stored in secretory granules and are released by exocytosis $[101,102]$. Both protein releasing processes should coincide temporarily and might involve similar signaling mechanisms/molecules. Concomitant release of proPO and the other proPO system components through a separate route was previously suggested [103]. On the other hand, TGase from horseshoe crabs are released from cytoplasm in response to LPS by an unknown mechanism, which do not involve cell lysis; in addition, LPS also induces secretory granule exocytosis [104]. Therefore, we could plausibly assume that TGase release to the external milieu is accomplished along with proPO zymogen by UPS, yet experimental evidences are needed. In addition, it would be interesting to known whether both proteins use the same mechanism. Alternatively, TGase could be secreted concomitant with the hyperpermeabilization of the plasma membrane which precedes cell lysis, as occur for IL-1ß in macrophages [94].

Figure 1 depicts a proposal for the mechanism for clotting process based on the hypothesis described above, and in a wealth of groundbreaking papers that have shed light about the activation and development of the proPO system and the clotting response in $P$. leniusculus.

In this species, TGase is located in semi-granular and granular cells. LPS and $\beta-1,3-\mathrm{D}-$ glucans induce degranulation by exocytosis of SGC [105], leading to the release of proPO system [17]. In this stage, cytoplasmic proPO zymogen is released [101], and probably also TGase. 
Among the released factors is peroxinectin, a $76 \mathrm{kDa}$ cell-adhesion protein that in addition to other biological functions, induce degranulation of SGC and GC [91, 106]. Peroxinectin is released as inactive protein from SGC and GC [107], and gains its activity by proteolysis promoted by the prophenoloxidase activating enzyme (ppA), a trypsin-like protease from the proPO cascade [108]. The ppA occur as zymogen and it is activated by microbial elicitors.

In addition, $\beta$-1,3-glucan-binding protein (BGBP) from plasma is activated upon binding to $\beta-1,3-\mathrm{D}$-glucans, and the complex is then bound to receptors in SGC and GC promoting further degranulation [17]. Such processes involve signaling pathways with protein kinase $\mathrm{C}$ and tyrosine phosphorylation [109]. However, it is not known whether the degranulating promoting activity exerted by peroxinectin and activated BGBP, may induce further releasing of TGase from cytoplasm, and hence, to burst the clotting response. Since both proteins act through the same receptors (Figure 1) [106, 110, 111], it is reasonable to expect that if any increase on TGase release happen, it would occur through a similar mechanism.

Finally, considering the apparent analogies suggested between the activation of the proPO system and the clotting response, it would be also plausible to suggest that activation of hemocytes and initiation of the clotting process could be mediated by similar intracellular signaling pathways [109] and molecules, such as soluble and membrane-bound pattern recognition receptors [17, 20, 112]. Other immune effectors such as lectins might be also involved. Future investigations are needed in order to address all these questions, which would also help to shed light about the relationship between the proPO system and the clotting response in crustacea.

Despite the usefulness of the freshwater crayfish model to comprehend these processes, it is evident that even among the few species studied some model deviations are noticed, mostly in the initiation stage, which is driven by the hemocyte type related with TGase release.

For instance, as stated earlier in this paper, in penaeid shrimps and probably in other species belonging to the type $\mathrm{C}$ coagulation mechanism, TGase is located mostly in hyaline cells from which are probably released by cell lysis. Hyaline cells are remarkably labile cells, insomuch that were named long ago as "explosive corpuscles" [14]. The mechanism leading to hyaline cell lysis is unknown. In the spiny lobster $P$. japonicus, granulocytes are the first cells to respond to Gram negative bacteria and LPS $[113,114]$, in this case, secretory granule exocytosis leads to the release of unknown 
mediators that bring about clotting and lysis of semi-granulocytes and hyaline cells. In insects, it has been identified several signaling pathways and receptors involved in the lysis of relevant hemocytes and the release of humoral proteins, such as cytoplasmic proPO [115-117]. In these species cells lysis can also occur in the absence of microbial elicitors through endogenous mediators [115].

Conversely to vertebrates, where the activation of the clotting reaction in the absence of microbial elicitors is well known to occur through the Tissue Factor from the extrinsic pathway [118], this process is barely understood in crustaceans and other invertebrates. Clotting activation in P. japonicus and other species can also be achieved in the absence of microbial elicitors (see [32] and references therein). In this case, it has been found that an unknown cytolytic factor from $P$. japonicus plasma rapidly induces the lysis of semigranular and hyaline cells in the presence of calcium leading to TGase releasing. The activation, regulation and the nature of the lytic factor(s) from plasma of spiny lobsters are still unknown. On the other hand, it has been recently found that LPS and other MAMPs induces the release of endogenous mediators from the hemocytes from shrimps, which in turn induces degranulation/lysis of the hemocytes among other immune responses [119]. Such endogenous mediators are composed by damageassociated molecular patterns (DAMPs) and other molecules, but the components responsible for the hemocyte response are yet to be identified.

Finally, how other factors affecting hemolymph homeostasis such as ionic strength and composition, which might also arise upon injury, influence hemocyte activation or lysis would require further studies.

\section{Pleiotropic functions of clotting system components.}

TGase were firstly recognized for its primary role in blood coagulation, but it is known that they are implicated in many other essential biological processes such as posttranslational modification of proteins, hardening of fertilization envelope and extracellular-matrix assembly, just to mention a few [83]. It has been described that TGase are involved in the regulation of immune-related genes in shrimps, especially antimicrobial peptides [120], while in freshwater crayfish and shrimp they are related with hematopoiesis $[35,121,122]$. Type II TGase from shrimps seems to be also involved in the regulation of carbohydrate metabolites [123]. It has been highlighted that whereas the human genome contains eight members of the TG family to fulfill the 
multiple functions of this enzyme [1], only one or two genes have been found in crustaceans up to date [19].

On the other hand, in addition to their main role as a clottable protein, crustacean CPs are also involved in lipid transport [62, 66, 124, 125], and hence included as part of the large lipid transfer protein (LLTP) superfamily responsible for circulatory lipid transport in animals [126]. It has been recently found that CP is a component of the extracellular matrix (ECM) proteins in the hematopoietic tissue of P. leniusculus, where it probably functions along with collagen, TGase and astakine 1 in controlling hematopoietic stem cell behavior [127]. In addition, $\mathrm{CP}$ is a possible nutritional source for shrimp embryo [128], and in the white shrimp P. vannamei shows peptidase activity under specific conditions [129], although the physiological meaning of such activity remains unknown.

\subsection{Clotting and immune response}

Hemolymph coagulation is mostly related with the immune response. The clearest evidence that relates clotting with immunity in crustacean and other arthropods is that the extracellular clots provide a physical barrier to the wound site that prevents microbial entrance to the hemocoel, and to entrap invading microbes avoiding their systemic dissemination $[1,3]$. This defense response is more relevant in arthropods than in vertebrates since they have an open circulatory system that implies higher risk for spreading microbial infection through the body cavity [1]. Likewise, the invertebrate body allows extensive clotting without the threat of thrombosis because disseminated coagulation is more harmless than in vertebrates [3].

Armstrong has pointed out that the presence of fibrinolytic protease systems as essential virulence factors for a broad variety of pathogens is an indirect evidence for the role of the clot in immunity $[130,131]$. The host has evolved to find ways to counter the microbial strategy. For instance, macroglobulin from the shrimp P. monodon is a suitable substrate for TGase and is cross-linked to CP in the clot where it inhibits proteases secreted by the entrapped pathogens, thus avoiding their dissemination [132].

Söderhäll and associates previously suggested the same process in freshwater crayfish [33]. The active participation of the clot in immunity has been recently demonstrated by its ability to capture and immobilize LPS [131]. 


\section{Concluding remarks}

Hemolymph clotting is a lifesaving response mostly because it prevents loss of hemolymph and maintains homeostasis. In addition, the clotting response in arthropods is actively involved in the immune response, as aid immobilization of microorganisms and their MAMP preventing their dissemination and facilitating their inactivation. Hemolymph coagulation in crustacean has been largely explained using the freshwater crayfish model (Fig. 1). Coagulation take place upon TGase release from hemocytes, which in presence of plasmatic calcium, promotes polymerization of the clotting protein with no additional intermediates. Both TGase and $\mathrm{CP}$ are multifunctional proteins engaged in other essential processes.

Although an increasing number of relevant studies are noticed in several shrimp species, the number of crustacean species studied is still limited. It has been recently highlighted the large quantity and diversity of crustacean species, and in addition, the great care that scientist should consider before stating general conclusions about certain biological process explained based on results obtained in a limited group of species [29].

Following this logical thought, it is conceivable the occurrence of certain degree of variation in the clotting response mechanism and its components among crustacean species. For instance, we identified differences in physic-chemistry properties among several clotting proteins. In addition, there are species containing cellular clottable protein, such as $O$. bipustulatus, but this protein is absented in many other. Most studies describing the occurrence of cellular coagulogen, which in some species seems to be related with the immune response, are really ancient. Thus, it would be interesting to confirm the existence and role of this protein in the clotting response using modern biology tools in a larger number of species.

It is remarkable that the participation of TGase in the clot formation has been conserved during evolution (from insects to mammals). TGase from crustacean shares similarities in sequence and properties such as the lack of a signal peptide and their location in the cytosol. However, the hemocyte type carrying TGase varies among crustacean species, which might lead to variations on how TGase is released and hence in clotting initiation. Considering the limited available information, it is tempting to suggest that in species in which TGase is mostly located in semi-granulocytes and granulocytes, TGase is released concomitant with the proPO system through an unknown unconventional protein secretion system. On the other hand, in those cases where TGase is mostly found in hyaline cells, it is probably released by rapid cell lysis as occur in insects for 
other leaderless cytosolic proteins that function in the external milieu (e.g. proPO zymogen), yet the mechanism engaged in cell lysis in crustaceans is still unknown. Further studies are required to elucidate the mechanisms and signaling pathways behind TGase releasing, which might represent an exciting niche for novel research in this field.

\section{Figure Caption}

Figure 1. A model for the initiation and development of the clotting response in the freshwater crayfish P. leniusculus. Transglutaminase (TGase) is located in semigranular (SGC) and granular cells (GC). Microbial elicitors such as $\beta-1,3-\mathrm{D}$-glucans (BG) directly induce degranulation of SGC and thus the releasing of proPO system components and other humoral factors. At this stage, leaderless cytoplasmic proteins such as proPO zymogen and TGase are probably released through an unknown unconventional protein secretion (UPS) system. Among the released factors by exocytosis is peroxinectin, a $76 \mathrm{kDa}$ protein able to promote degranulation of SGC and GC. Peroxinectin is released as inactive protein from SGC and GC (pro-peroxinectin), and acquire its activity by limited proteolysis promoted by the prophenoloxidase activating enzyme (ppA), a trypsin-like proteinase from the proPO cascade. The ppA also occur as zymogen (pro-ppA) and is activated by microbial elicitors. In addition, $\beta$ 1,3-glucan-binding protein (BGBP) from plasma is activated upon binding to $\mathrm{BG}$, and the complex is then bound to receptors in SGC and GC promoting further degranulation. Both peroxinectin and BG-BGBP complex triggers the degranulation response in SGC and GC upon binding to a $90-\mathrm{kDa}$ peripheral cell surface superoxide dismutase receptor (CuZn-SOD) and to a transmembrane integrin protein. Finally, TGase is activated in the plasma by calcium and promotes the polymerization of the clotting protein $(\mathrm{CP})$. 


\section{References}

[1] T.G. Loof, O. Schmidt, H. Herwald, U. Theopold, Coagulation systems of invertebrates and vertebrates and their roles in innate immunity: the same side of two coins?, J Innate Immun 3(1) (2011) 34-40.

[2] P. Jiravanichpaisal, B.L. Lee, K. Söderhäll, Cell-mediated immunity in arthropods: hematopoiesis, coagulation, melanization and opsonization, Immunobiology 211(4) (2006) 213-36.

[3] U. Theopold, O. Schmidt, K. Söderhäll, M.S. Dushay, Coagulation in arthropods: defence, wound closure and healing, Trends Immunol 25(6) (2004) 289-94.

[4] S.L. Diamond, Systems biology of coagulation, J Thromb Haemost 11 Suppl 1 (2013) 224-32.

[5] D.C. Baker, J. Brassard, Review of continuing education course on hemostasis, Toxicol Pathol 39(1) (2011) 281-8.

[6] H.H. Versteeg, J.W. Heemskerk, M. Levi, P.H. Reitsma, New fundamentals in hemostasis, Physiol Rev 93(1) (2013) 327-58.

[7] D.M. Monroe, M. Hoffman, What does it take to make the perfect clot?, Arterioscler Thromb Vasc Biol 26(1) (2006) 41-8.

[8] S. Iwanaga, B.L. Lee, Recent advances in the innate immunity of invertebrate animals, J Biochem Mol Biol 38(2) (2005) 128-50.

[9] S. Kawabata, Immunocompetent molecules and their response network in horseshoe crabs, Adv Exp Med Biol 708 (2010) 122-36.

[10] F.W. Harrison, A.G. Humes, Microscopic Anatomy of Invertebrates, Decapod Crustacea, Wiley1992.

[11] U. Theopold, R. Krautz, M.S. Dushay, The Drosophila clotting system and its messages for mammals, Dev Comp Immunol 42(1) (2014) 42-6.

[12] M. Dushay, Insect hemolymph clotting, Cell Mol Life Sci 66(16) (2009) 26432650.

[13] M. Durliat, Clotting processes in crustacea decapoda, Biol Rev 60 (1985) 473-498.

[14] M.H. Ravindranath, Haemocytes in haemolymph coagulation of arthropods, Biol Rev 55 (1980) 139-170.

[15] K. Sritunyalucksana, K. Söderhäll, The proPO and clotting system in crustaceans, Aquaculture 191(1-3) (2000) 53-69. 
[16] L. Cerenius, S. Kawabata, B.L. Lee, M. Nonaka, K. Söderhäl, Proteolytic cascades and their involvement in invertebrate immunity, Trends Biochem Sci 35(10) (2010) $575-83$.

[17] S.Y. Lee, K. Söderhäll, Early events in crustacean innate immunity, Fish Shellfish Immunol 12(5) (2002) 421-37.

[18] S. Srimal, Blood clotting in invertebrates, Prog Mol Subcell Biol 15 (1996) 88-100.

[19] L. Cerenius, K. Söderhäll, Coagulation in invertebrates, J Innate Immun 3(1) (2011) 3-8.

[20] L. Cerenius, K. Söderhäll, Crayfish immunity - Recent findings, Dev Comp Immunol 80 (2018) 94-98.

[21] A. Tassanakajon, K. Somboonwiwat, P. Supungul, S. Tang, Discovery of immune molecules and their crucial functions in shrimp immunity, Fish Shellfish Immunol 34(4) (2013) 954-67.

[22] M.B. Maningas, H. Kondo, I. Hirono, Molecular mechanisms of the shrimp clotting system, Fish Shellfish Immunol 34(4) (2013) 968-72.

[23] J. Tait, Types of crustacean blood coagulation, J Mar Biol Assoc (UK) 9 (1911) 191-198.

[24] G.G. Martin, J.E.H.S. Omori, C. Chong, T. Hoodbhoy, N. McKrell, Localization and roles of coagulogen and transglutaminase in hemolymph coagulation in decapod crustaceans, Comp Biochem Physiol B 100(3) (1991) 517-522.

[25] J.E. Hose, G.G. Martin, A.S. Gerard, A decapod hemocyte classification scheme integrating morphology, cytochemistry, and function, Biol Bull 178 (1990) 33-45. [26] G.G. Martin, H.M. Lin, C. Luc, Reexamination of hemocytes in brine shrimp (Crustacea, branchiopoda), J Morphol 242(3) (1999) 283-94.

[27] W. Ghidalia, R. Vendrely, C. Montmory, Y. Coirault, M.O. Brouard, Coagulation in decapod crustacea, J Comp Physiol B 142(4) (1981) 473-478.

[28] G.G. Martin, J.E. Hose, Vascular elements and blood (hemolymph), in: F.W. Harrison (Ed.), Microscopic Anatomy of Invertebrates, Wiley-Liss, New York, 1992, pp. 117-146.

[29] I. Söderhäll, Crustacean hematopoiesis, Dev Comp Immunol 58 (2016) 129-41. [30] V. Matozzo, M.G. Marin, First cytochemical study of haemocytes from the crab Carcinus aestuarii (Crustacea, Decapoda), Eur J Histochem 54(1) (2010) e9. 
[31] D. Parrinello, M. Sanfratello, M. Celi, M. Vazzana, Hemocyte types and some plasmatic properties of two edible crabs Cancer borealis and Cancer pagurus, IJS 12 (2015) 195-202.

[32] H. Aono, K. Mori, Interaction between hemocytes and plasma is necessary for hemolymph coagulation in the spiny lobster, Panulirus japonicus, Comp Biochem Physiol A Physiol 113(3) (1996) 301-305.

[33] R. Wang, Z. Liang, M. Hal, K. Söderhäll, A transglutaminase involved in the coagulation system of the freshwater crayfish, Pacifastacus leniusculus. Tissue localisation and cDNA cloning, Fish Shellfish Immunol 11(7) (2001) 623-37. [34] M.-S. Yeh, C.-H. Liu, C.-W. Hung, W. Cheng, cDNA cloning, identification, tissue localisation, and transcription profile of a transglutaminase from white shrimp, Litopenaeus vannamei, after infection by Vibrio alginolyticus, Fish Shellfish Immunol 27(6) (2009) 748-756.

[35] C.-C. Huang, K. Sritunyalucksana, K. Söderhäll, Y.-L. Song, Molecular cloning and characterization of tiger shrimp (Penaeus monodon) transglutaminase, Dev Comp Immunol 28(4) (2004) 279-294.

[36] M.Y. Chen, K.Y. Hu, C.C. Huang, Y.L. Song, More than one type of transglutaminase in invertebrates? A second type of transglutaminase is involved in shrimp coagulation, Dev Comp Immunol 29(12) (2005) 1003-16.

[37] L.M. Perazzolo, D.M. Lorenzini, S. Daffre, M.A. Barracco, Purification and partial characterization of the plasma clotting protein from the pink shrimp Farfantepenaeus paulensis, Comp Biochem Physiol B Biochem Mol Biol 142(3) (2005) 302-7. [38] Y.C. Liu, F.H. Li, B. Wang, B. Dong, Q.L. Zhang, W. Luan, X.J. Zhang, J.H. Xiang, A transglutaminase from Chinese shrimp (Fenneropenaeus chinensis), fulllength cDNA cloning, tissue localization and expression profile after challenge, Fish Shellfish Immunol 22(5) (2007) 576-88.

[39] M.S. Yeh, Y.L. Chen, I.H. Tsai, The hemolymph clottable proteins of tiger shrimp, Penaeus monodon, and related species, Comp Biochem Physiol B Biochem Mol Biol 121(2) (1998) 169-76.

[40] B.M. von Reumont, R.A. Jenner, M.A. Wills, E. Dell'ampio, G. Pass, I. Ebersberger, B. Meyer, S. Koenemann, T.M. Iliffe, A. Stamatakis, O. Niehuis, K. Meusemann, B. Misof, Pancrustacean phylogeny in the light of new phylogenomic data: support for Remipedia as the possible sister group of Hexapoda, Mol Biol Evol 29(3) (2012) 1031-45. 
[41] M. Hall, R. Wang, R. van Antwerpen, L. Sottrup-Jensen, K. Söderhäll, The crayfish plasma clotting protein: a vitellogenin-related protein responsible for clot formation in crustacean blood, Proc Natl Acad Sci U S A 96(5) (1999) 1965-70. [42] G.M. Fuller, R.F. Doolittle, Studies of invertebrate fibrinogen. II. Transformation of lobster fibrinogen into fibrin, Biochemistry 10(8) (1971) 1311-5.

[43] P. Kopacek, M. Hall, K. Söderhäll, Characterization of a clotting protein, isolated from plasma of the freshwater crayfish Pacifastacus leniusculus, Eur J Biochem 213(1) (1993) 591-7.

[44] W. Ghidalia, R. Vendrely, C. Montmory, Y. Coirault, Cross induced coagulations between human and crustacean clotting factors. Considerations on the clotting processes, Comp Biochem Physiol A Comp Physiol 72(4) (1982) 741-5.

[45] S.A. Omori, G.G. Martin, J.E. Hose, Morphology of hemocyte lysis and clotting in the ridgeback prawn, Sicyonia ingentis Cell Tissue Res 255(1) (1989) 117-123.

[46] F. Madaras, J.D. Parkin, P.A. Castaldi, Coagulation in the sand crab (Ovalipes bipustulatus), Thromb Haemost 42(2) (1979) 734-42.

[47] F. Madaras, M.Y. Chew, J.D. Parkin, Purification and characterization of the sand crab (Ovalipes bipustulatus) coagulogen (fibrinogen), Thromb Haemost 45(1) (1981) 77-81.

[48] K. Montaño-Pérez, G. Yepiz-Plascencia, I. Higuera-Ciapara, F. Vargas-Albores, Purification and characterization of the clotting protein from the white shrimp Penaeus vannamei, Comp Biochem Physiol B Biochem Mol Biol 122 (1999) 381-387.

[49] K. Söderhäll, Fungal cell wall beta-1,3-glucans induce clotting and phenoloxidase attachment to foreign surfaces of crayfish hemocyte lysate, Dev Comp Immunol 5(4) (1981) 565-73.

[50] K. Söderhäll, L. Häll, Lipopolysaccharide-induced activation of prophenoloxidase activating system in crayfish haemocyte lysate, Biochim Biophys Acta 797(1) (1984) 99-104.

[51] A.D. Pearson, M.W. Calder, P.D. Meers, Assay of endotoxin, Lancet 1(7813) (1973) 1194-5.

[52] M. Durliat, R. Vranckx, Relationships between plasma and hemocyte proteins in Decapoda, Comp Biochem Physiol B Comp Biochem 92(4) (1989) 595-603.

[53] M.O. Salawu, O.B. Oloyede, Endotoxin-induced coagulation reactions and phenoloxidase activity modulation in Sudanonautes africanus hemolymph fractions, $\mathbf{J}$ Immunotoxicol 8(4) (2011) 324-32. 
[54] C. Biswas, C. Mandal, The role of amoebocytes in endotoxin-mediated coagulation in the innate immunity of Achatina fulica snails, Scand J Immunol 49(2) (1999) 131-8. [55] C. Biswas, D. Sinha, C. Mandal, Investigation on interaction of Achatinin, a 9-Oacetyl sialic acid-binding lectin, with lipopolysaccharide in the innate immunity of Achatina fulica snails, Mol Immunol 37(12-13) (2000) 745-54.

[56] J.A. Marcum, J. Levin, R.A. Prendergast, Clotting enzyme activity derived from the coelomocytes of the sea star Asterias forbesi, Thromb Haemost 52(1) (1984) 1-3. [57] S. Lorenzon, S. de Guarrini, V.J. Smith, E.A. Ferrero, Effects of LPS injection on circulating haemocytes in crustaceansin vivo, Fish Shellfish Immunol 9(1) (1999) 3150.

[58] J. Levin, Blood coagulation and endotoxin in invertebrates, Fed Proc 26(6) (1967) 1707-1712.

[59] B. Beutler, E.T. Rietschel, Innate immune sensing and its roots: the story of endotoxin, Nat Rev Immunol 3(2) (2003) 169-76.

[60] M.W. Johansson, K. Söderhäll, Cellular immunity in crustaceans and the proPO system, Parasitol Today 5(6) (1989) 171-6.

[61] K. Söderhäll, L. Cerenius, Crustacean immunity, Annu Rev Fish Dis 2 (1992) 323.

[62] G. Yepiz-Plascencia, F. Jimenez-Vega, M.G. Romo-Figueroa, R.R. Sotelo-Mundo, F. Vargas-Albores, Molecular characterization of the bifunctional VHDL-CP from the hemolymph of white shrimp Penaeus vannamei, Comp Biochem Physiol B Biochem Mol Biol 132(3) (2002) 585-92.

[63] G.M. Fuller, R.F. Doolittle, Studies of invertebrate fibrinogen. I. Purification and characterization of fibrinogen from the spiny lobster, Biochemistry 10(8) (1971) 130511.

[64] R.F. Doolittle, G.M. Fuller, Sodium dodecyl sulfate-polyacrylamide gel electrophoresis studies on lobster fibrinogen and fibrin, Biochim Biophys Acta 263(3) (1972) 805-9.

[65] W. Cheng, I.H. Tsai, C.J. Huang, P.C. Chiang, C.H. Cheng, M.S. Yeh, Cloning and characterization of hemolymph clottable proteins of kuruma prawn (Marsupenaeus japonicus) and white shrimp (Litopenaeus vannamei), Dev Comp Immunol 32(3) (2008) 265-74. 
[66] M. Komatsu, S. Ando, A very-high-density lipoprotein with clotting ability from hemolymph of sand crayfish, Ibacus ciliatus, Biosci Biotechnol Biochem 62(3) (1998) 459-63.

[67] M.S. Yeh, C.J. Huang, J.H. Leu, Y.C. Lee, I.H. Tsai, Molecular cloning and characterization of a hemolymph clottable protein from tiger shrimp (Penaeus monodon), Eur J Biochem 266(2) (1999) 624-33.

[68] B. Wang, H. Peng, M. Liu, K. Jiang, G. Zhang, L. Wang, Purification and identification of a clotting protein from the hemolymph of Chinese shrimp (Fenneropenaeus chinensis), J Ocean Univ China 12(3) (2013) 477-483.

[69] M.L. Porter, M. Perez-Losada, K.A. Crandall, Model-based multi-locus estimation of decapod phylogeny and divergence times, Mol Phylogenet Evol 37(2) (2005) 355-69. [70] S. Iwanaga, S. Gokudan, J. Mizuguchi, Molecular Evolution of Blood Clotting Factors with Special Reference to Fibrinogen and von Willebrand Factor, in: K. Tanaka, E. Davie, Y. Ikeda, S. Iwanaga, H. Saito, K. Sueishi (Eds.), Recent Advances in Thrombosis and Hemostasis 2008, Springer Japan2008, pp. 439-461.

[71] P.C. Hanington, S.M. Zhang, The primary role of fibrinogen-related proteins in invertebrates is defense, not coagulation, J Innate Immun 3(1) (2011) 17-27.

[72] I. Söderhäll, C. Wu, M. Novotny, B.L. Lee, K. Söderhäll, A novel protein acts as a negative regulator of prophenoloxidase activation and melanization in the freshwater crayfish Pacifastacus leniusculus, J Biol Chem 284(10) (2009) 6301-10.

[73] P. Angthong, A. Watthanasurorot, S. Klinbunga, U. Ruangdej, I. Söderhäll, P. Jiravanichpaisal, Cloning and characterization of a melanization inhibition protein (PmMIP) of the black tiger shrimp, Penaeus monodon, Fish Shellfish Immunol 29(3) (2010) 464-8.

[74] C. Wu, K. Söderhäll, I. Söderhäll, Two novel ficolin-like proteins act as pattern recognition receptors for invading pathogens in the freshwater crayfish Pacifastacus leniusculus, Proteomics 11(11) (2011) 2249-64.

[75] J.J. Sun, J.F. Lan, X.Z. Shi, M.C. Yang, H.T. Yang, X.F. Zhao, J.X. Wang, A fibrinogen-related protein (FREP) is involved in the antibacterial immunity of Marsupenaeus japonicus, Fish Shellfish Immunol 39(2) (2014) 296-304.

[76] S.Y. Lee, B.L. Lee, K. Söderhäll, Processing of crayfish hemocyanin subunits into phenoloxidase, Biochem Biophys Res Commun 322(2) (2004) 490-6. 
[77] S.Y. Lee, B.L. Lee, K. Söderhäll, Processing of an antibacterial peptide from hemocyanin of the freshwater crayfish Pacifastacus leniusculus, J Biol Chem 278(10) (2003) 7927-33.

[78] M.G. Romo-Figueroa, C. Vargas-Requena, R.R. Sotelo-Mundo, F. VargasAlbores, I. Higuera-Ciapara, K. Söderhäll, G. Yepiz-Plascencia, Molecular cloning of a beta-glucan pattern-recognition lipoprotein from the white shrimp Penaeus (Litopenaeus) vannamei: correlations between the deduced amino acid sequence and the native protein structure, Dev Comp Immunol 28(7-8) (2004) 713-26.

[79] L. Cerenius, Z. Liang, B. Duvic, P. Keyser, U. Hellman, E.T. Palva, S. Iwanaga, K. Söderhäll, Structure and biological activity of a 1,3-beta-D-glucan-binding protein in crustacean blood, J Biol Chem 269(47) (1994) 29462-7.

[80] M.-S. Yeh, C.-J. Huang, J.-H. Cheng, I.-H. Tsai, Tissue-specific expression and regulation of the haemolymph clottable protein of tiger shrimp (Penaeus monodon), Fish Shellfish Immunol 23(2) (2007) 272-279.

[81] A. Ichinose, R.E. Bottenus, E.W. Davie, Structure of transglutaminases, J Biol Chem 265(23) (1990) 13411-4.

[82] L. Lorand, S.M. Conrad, Transglutaminases, Mol Cell Biochem 58(1-2) (1984) 935 .

[83] L. Lorand, R.M. Graham, Transglutaminases: crosslinking enzymes with pleiotropic functions, Nat Rev Mol Cell Biol 4(2) (2003) 140-56.

[84] D. Park, S.S. Choi, K.S. Ha, Transglutaminase 2: a multi-functional protein in multiple subcellular compartments, Amino Acids 39(3) (2010) 619-31.

[85] B. Ahvazi, H.C. Kim, S.H. Kee, Z. Nemes, P.M. Steinert, Three-dimensional structure of the human transglutaminase 3 enzyme: binding of calcium ions changes structure for activation, EMBO J 21(9) (2002) 2055-67.

[86] R. Sirikharin, K. Junkunlo, K. Söderhäll, I. Söderhäll, Role of astakine1 in regulating transglutaminase activity, Dev Comp Immunol 76 (2017) 77-82.

[87] M.S. Yeh, L.R. Kao, C.J. Huang, I.H. Tsai, Biochemical characterization and cloning of transglutaminases responsible for hemolymph clotting in Penaeus monodon and Marsupenaeus japonicus, Biochim Biophys Acta 1764(7) (2006) 1167-78.

[88] J. Arockiaraj, A.J. Gnanam, R. Palanisamy, V. Kumaresan, P. Bhatt, M.K. Thirumalai, A. Roy, M. Pasupuleti, M. Kasi, A. Sathyamoorthi, A. Arasu, A prawn transglutaminase: molecular characterization and biochemical properties, Biochimie 95(12) (2013) 2354-64. 
[89] M.S. Yeh, W.L. Tsai, W. Cheng, Identification and cloning of the second type transglutaminase from Litopenaeus vannamei, and its transcription following pathogen infection and in relation to the haemolymph coagulation, Fish Shellfish Immunol 35(5) (2013) 1613-23.

[90] E. Ruoslahti, RGD and other recognition sequences for integrins, Annu Rev Cell Dev Biol 12 (1996) 697-715.

[91] T. Holmblad, K. Söderhäll, Cell adhesion molecules and antioxidative enzymes in a crustacean, possible role in immunity, Aquaculture 172(1-2) (1999) 111-123.

[92] M.W. Johansson, K. Söderhäll, A peptide containing the cell adhesion sequence RGD can mediate degranulation and cell adhesion of crayfish granular haemocytes in vitro, Insect Biochem 19(6) (1989) 573-579.

[93] W. Nickel, C. Rabouille, Mechanisms of regulated unconventional protein secretion, Nat Rev Mol Cell Biol 10(2) (2009) 148-55.

[94] C. Rabouille, Pathways of Unconventional Protein Secretion, Trends Cell Biol 27(3) (2017) 230-240.

[95] T. Shibata, J. Hadano, D. Kawasaki, X. Dong, S.I. Kawabata, Drosophila TG-A transglutaminase is secreted via an unconventional Golgi-independent mechanism involving exosomes and two types of fatty acylations, J Biol Chem 292(25) (2017) 10723-10734.

[96] R.L. Eckert, M.T. Kaartinen, M. Nurminskaya, A.M. Belkin, G. Colak, G.V. Johnson, K. Mehta, Transglutaminase regulation of cell function, Physiol Rev 94(2) (2014) 383-417.

[97] L. Diaz-Hidalgo, S. Altuntas, F. Rossin, M. D'Eletto, C. Marsella, M.G. Farrace, L. Falasca, M. Antonioli, G.M. Fimia, M. Piacentini, Transglutaminase type 2-dependent selective recruitment of proteins into exosomes under stressful cellular conditions, Biochim Biophys Acta 1863(8) (2016) 2084-92.

[98] E.A. Zemskov, I. Mikhailenko, R.C. Hsia, L. Zaritskaya, A.M. Belkin, Unconventional secretion of tissue transglutaminase involves phospholipid-dependent delivery into recycling endosomes, PLoS One 6(4) (2011) e19414.

[99] M. Adamczyk, R. Griffiths, S. Dewitt, V. Knauper, D. Aeschlimann, P2X7 receptor activation regulates rapid unconventional export of transglutaminase-2, J Cell Sci 128(24) (2015) 4615-28.

[100] I. Eleftherianos, C. Revenis, Role and importance of phenoloxidase in insect hemostasis, J Innate Immun 3(1) (2011) 28-33. 
[101] M. Jearaphunt, C. Noonin, P. Jiravanichpaisal, S. Nakamura, A. Tassanakajon, I. Soderhall, K. Soderhall, Caspase-1-like regulation of the proPO-system and role of ppA and caspase-1-like cleaved peptides from proPO in innate immunity, PLoS Pathog 10(4) (2014) e1004059.

[102] S. Sricharoen, J.J. Kim, S. Tunkijjanukij, I. Soderhall, Exocytosis and proteomic analysis of the vesicle content of granular hemocytes from a crayfish, Dev Comp Immunol 29(12) (2005) 1017-31.

[103] L. Cerenius, B.L. Lee, K. Söderhäll, The proPO-system: pros and cons for its role in invertebrate immunity, Trends Immunol 29(6) (2008) 263-71.

[104] T. Osaki, N. Okino, F. Tokunaga, S. Iwanaga, S. Kawabata, Proline-rich cell surface antigens of horseshoe crab hemocytes are substrates for protein cross-linking with a clotting protein coagulin, J Biol Chem 277(42) (2002) 40084-40090.

[105] M.W. Johansson, K. Söderhäll, Exocytosis of the prophenoloxidase activating system from crayfish haemocytes, Journal of Comparative Physiology B 156(2) (1985) 175-181.

[106] O. Schmidt, K. Söderhäll, U. Theopold, I. Faye, Role of adhesion in arthropod immune recognition, Annu Rev Entomol 55 (2010) 485-504.

[107] M.W. Johansson, K. Söderhäll, Isolation and purification of a cell adhesion factor from crayfish blood cells, J Cell Biol 106(5) (1988) 1795-803.

[108] X. Lin, L. Cerenius, B.L. Lee, K. Söderhäll, Purification of properoxinectin, a myeloperoxidase homologue and its activation to a cell adhesion molecule, Biochim Biophys Acta 1770(1) (2007) 87-93.

[109] M.W. Johansson, K. Soderhall, Intracellular signaling in arthropod blood cells: involvement of protein kinase $\mathrm{C}$ and protein tyrosine phosphorylation in the response to the 76-kDa protein or the beta-1,3-glucan-binding protein in crayfish, Dev Comp Immunol 17(6) (1993) 495-500.

[110] M.W. Johansson, Cell adhesion molecules in invertebrate immunity, Dev Comp Immunol 23(4-5) (1999) 303-15.

[111] M.W. Johansson, T. Holmblad, P.O. Thornqvist, M. Cammarata, N. Parrinello, K. Söderhäll, A cell-surface superoxide dismutase is a binding protein for peroxinectin, a cell-adhesive peroxidase in crayfish, J Cell Sci 112 ( Pt 6) (1999) 917-25.

[112] L. Cerenius, K. Söderhäll, The prophenoloxidase-activating system in invertebrates, Immunol Rev 198 (2004) 116-26. 
[113] A. Hideaki, O. Ichiro, M. Katsuyoshi, Cell type-specific roles in the hemocyte clotting system of the spiny lobster, Panulirus japonicus, Comp Biochem Physiol A Physiol 105(1) (1993) 11-15.

[114] A. Hideaki, D. Gabriel Gómez, M. Katsuyoshi, Granular cells recognize non-self signals and trigger the clotting reaction of hemocytes in vitro in the spiny lobster, Panulirus japonicus, Comp Biochem Physiol A Physiol 107(1) (1994) 37-42. [115] G. Bidla, M.S. Dushay, U. Theopold, Crystal cell rupture after injury in Drosophila requires the JNK pathway, small GTPases and the TNF homolog Eiger, J Cell Sci 120(Pt 7) (2007) 1209-15.

[116] S. Shrestha, D. Stanley, Y. Kim, PGE(2) induces oenocytoid cell lysis via a G protein-coupled receptor in the beet armyworm, Spodoptera exigua, J Insect Physiol 57(11) (2011) 1568-76.

[117] S. Shrestha, J. Park, S.J. Ahn, Y. Kim, Pge2 Mediates Oenocytoid Cell Lysis Via a Sodium-Potassium-Chloride Cotransporter, Arch Insect Biochem Physiol 89(4) (2015) 218-29.

[118] D. Gailani, T. Renne, Intrinsic pathway of coagulation and arterial thrombosis, Arterioscler Thromb Vasc Biol 27(12) (2007) 2507-13.

[119] Y.Y. Chen, J.C. Chen, Y.C. Lin, S. Kitikiew, H.F. Li, J.C. Bai, K.C. Tseng, B.W. Lin, P.C. Liu, Y.Z. Shi, Y.H. Kuo, Y.H. Chang, Endogenous molecules induced by a pathogen-associated molecular pattern (PAMP) elicit innate immunity in shrimp, PLoS One 9(12) (2014) e115232.

[120] F.F. Fagutao, M.B. Maningas, H. Kondo, T. Aoki, I. Hirono, Transglutaminase regulates immune-related genes in shrimp, Fish Shellfish Immunol 32(5) (2012) 711-5. [121] X. Lin, K. Söderhäll, I. Söderhäll, Transglutaminase activity in the hematopoietic tissue of a crustacean, Pacifastacus leniusculus, importance in hemocyte homeostasis, BMC Immunol 9 (2008) 58.

[122] Y.T. Chang, C.Y. Lin, C.Y. Tsai, V.S. Siva, C.Y. Chu, H.J. Tsai, Y.L. Song, The new face of the old molecules: crustin Pm4 and transglutaminase type I serving as rnps down-regulate astakine-mediated hematopoiesis, PLoS One 8(8) (2013) e72793.

[123] Y.N. Chen, W.C. Chen, W. Cheng, The second type of transglutaminase regulates immune and stress responses in white shrimp, Litopenaeus vannamei, Fish Shellfish Immunol 37(1) (2014) 30-7. 
[124] M. Hall, M.C. van Heusden, K. Söderhäll, Identification of the major lipoproteins in crayfish hemolymph as proteins involved in immune recognition and clotting, Biochem Biophys Res Commun 216(3) (1995) 939-46.

[125] J.M. Kollman, J. Quispe, The 17A structure of the $420 \mathrm{kDa}$ lobster clottable protein by single particle reconstruction from cryoelectron micrographs, J Struct Biol 151(3) (2005) 306-14.

[126] M.M. Smolenaars, O. Madsen, K.W. Rodenburg, D.J. Van der Horst, Molecular diversity and evolution of the large lipid transfer protein superfamily, J Lipid Res 48(3) (2007) 489-502.

[127] K. Junkunlo, K. Söderhäll, I. Söderhäll, Clotting protein - An extracellular matrix (ECM) protein involved in crustacean hematopoiesis, Dev Comp Immunol 78 (2018) 132-140.

[128] W. Cheng, P.C. Chiang, C.Y. Lai, M.S. Yeh, Expression of clottable protein of tiger shrimp (Penaeus monodon) in gonads and its possible role as nutrient source for the embryo, Dev Comp Immunol 32(12) (2008) 1422-9.

[129] T. Reyes-Izquierdo, F. Vargas-Albores, Proteinase activity in the white shrimp (Penaeus vannamei) clotting protein, Biochem Biophys Res Commun 287(2) (2001) $332-6$.

[130] P.B. Armstrong, Proteases and protease inhibitors: a balance of activities in hostpathogen interaction, Immunobiology 211(4) (2006) 263-81.

[131] M.T. Armstrong, F.R. Rickles, P.B. Armstrong, Capture of lipopolysaccharide (endotoxin) by the blood clot: a comparative study, PLoS One 8(11) (2013) e80192. [132] V. Chaikeeratisak, K. Somboonwiwat, A. Tassanakajon, Shrimp alpha-2macroglobulin prevents the bacterial escape by inhibiting fibrinolysis of blood clots, PLoS One 7(10) (2012) e47384. 


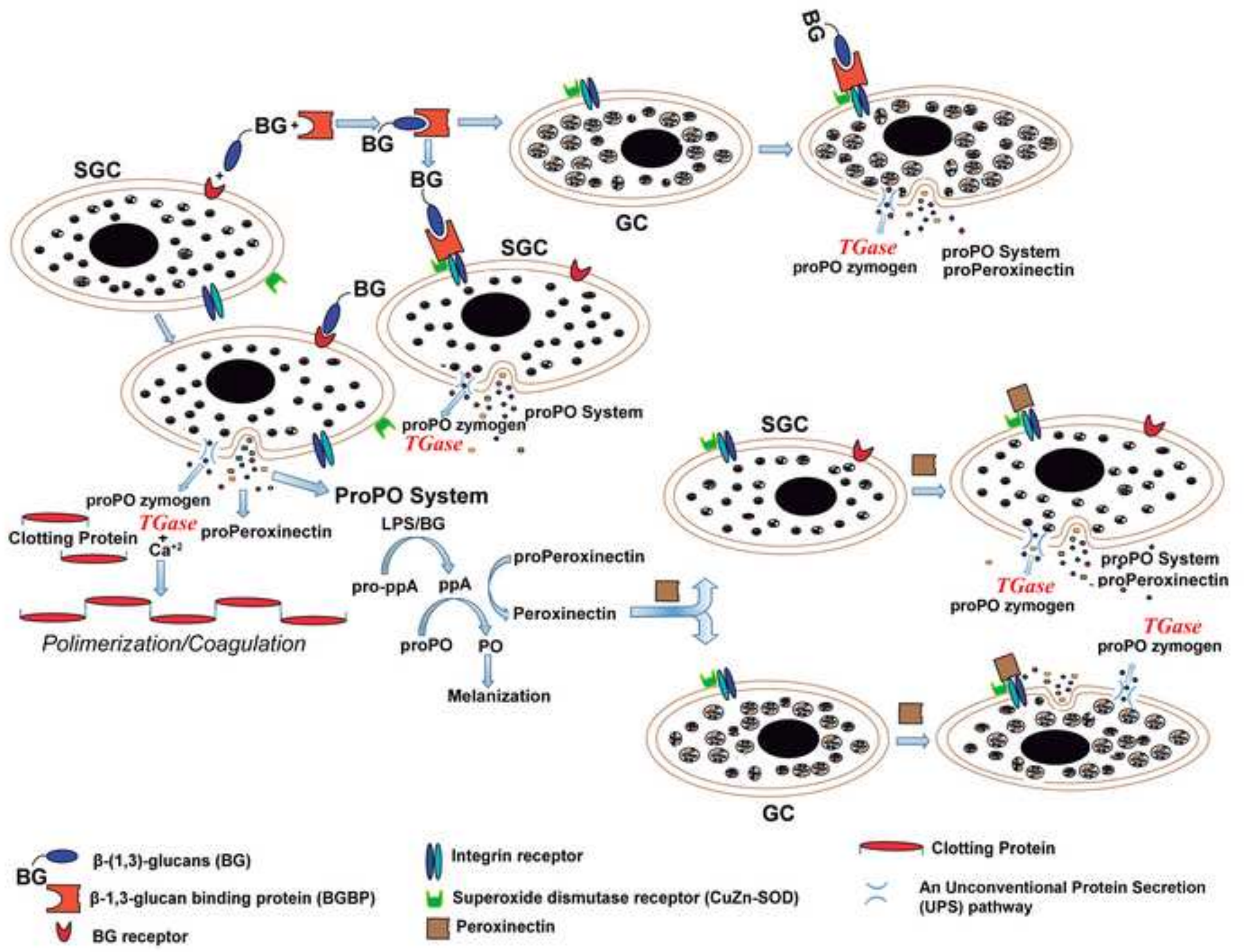




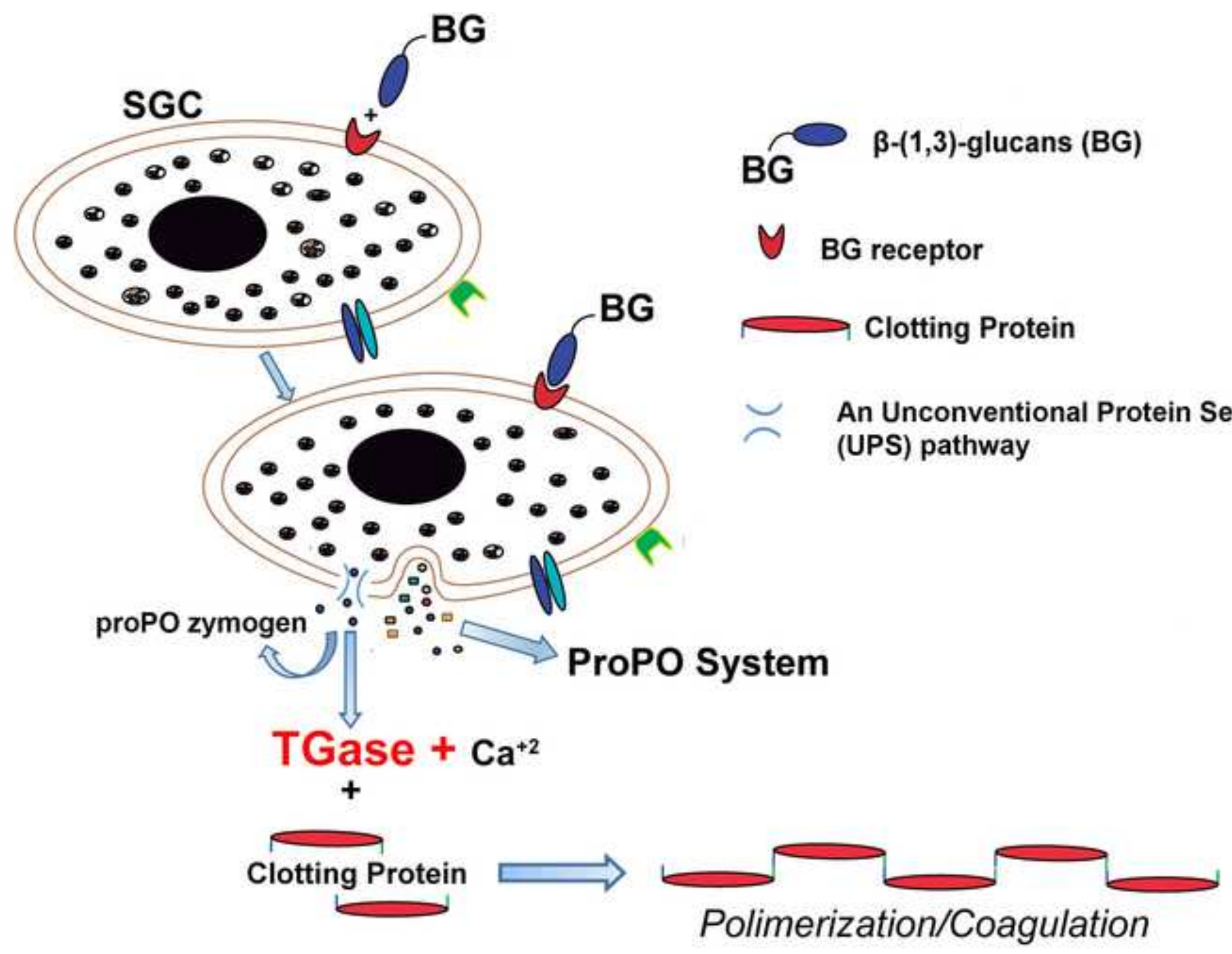

